\title{
UNCERTAINTY IN THE NUMERICAL MODELLING OF MASONRY TRIPLET TESTS UNDER DYNAMIC LOADING
}

\author{
M. MENDOZA PUCHADES ${ }^{1,2,3}$, R. JUDGE ${ }^{1,2,3}$ \& G. BEATTIE ${ }^{3}$ \\ ${ }^{1}$ Institute for Risk and Uncertainty, University of Liverpool, UK \\ ${ }^{2}$ School of Engineering, University of Liverpool, UK \\ ${ }^{3}$ Arup, Liverpool, UK
}

\begin{abstract}
Masonry structures have been broadly used worldwide for centuries. These structures are likely to be subjected to seismic movements, malicious or accidental blast and/or impact loading. Expanding the current body of knowledge of how masonry structures perform under such conditions and developing reliable and robust modelling techniques is essential to improve both the efficiency and safety of the design and retrofitting of such structures. A great deal of research is currently ongoing to understand the behaviour of masonry under shock and impact loading, and this is proving to be a challenging endeavour. Masonry construction on the whole is surrounded by a high degree of variability ranging from the heterogeneity of the materials used, the degree of workmanship during construction and the uncertainty regarding the physical and mechanical properties of the brick-to-mortar interface. Masonry is known to experience a dynamic enhancement of its strength properties when subjected to impact loading and dynamic increase factors (DIFs) have been used to adjust static masonry properties accordingly when subjected to this type of loading. These DIFs are derived from sparse experimental tests and their use can be severely limited to the conditions of the tests performed, and the results obtained can carry a high degree of uncertainty. This paper considers the uncertainty present at the brick-to-mortar interface, by using Monte Carlo simulations, when subjected to dynamic loading in a standard triplet test using LS-DYNA. The results of the modelling have been compared, contrasted and discussed for use in a larger research project on the robust characterisation of masonry structures when subjected to blast and seismic loading.

Keywords: blast, impact, masonry, seismic, shear strength, uncertainty.
\end{abstract}

\section{INTRODUCTION}

Masonry is one of the oldest construction materials, and it is extensively used worldwide. Masonry structures are required to withstand both in-plane and out-of-plane actions such as those arising from seismic events or blast scenarios (accidental or malicious). Therefore, understanding and efficiently predicting the behaviour of masonry structures under such loading conditions is of high importance to achieve the most proficient design solutions.

Masonry is a heterogeneous material formed by clay bricks, concrete blocks or even stones of different shapes and composition joined together with mortar, which can be mixed with different additives to enhance its strength. This heterogeneity leads to an anisotropic behaviour, which is also influenced by variations in the quality of workmanship (in situ layering process), bond behaviour at the brick-to-mortar interfaces, the level of water content in the bricks and mortar, the surface features of the bricks (rough, smooth or frogged) and weathering. These features render masonry modelling and design with high levels of 
uncertainty and variability. This paper deals with some uncertainty present in masonry design and construction, and it aims to propagate some uncertainty present at brick-to-mortar interface in a finite element model.

\section{MASONRY DESIGN}

\subsection{Static design}

Design guidance is available for masonry structures subjected to static loading, such as Eurocode 6 in Europe and ACI 530-13 in the United States. Large factors of safety are applied to the material to account for the high level of uncertainty previously highlighted. In Eurocode 6 , a factor of safety as high as 3 is suggested for some construction scenarios. This is considerably higher when compared to other factors of safety provided by Eurocodes, such as that for reinforced concrete (1.5) or steel (1.05). When dealing with more specific material composition, these codes can lead to inefficient design, e.g. Wang et al. [1] found Eurocode 6 to be conservative for blue brick and hydraulic premixed mortar structures when subject to static loading.

\subsection{Current modelling approaches for dynamic and/or out-of-plane actions}

A high level of variability and uncertainty is present when characterising masonry response to dynamic and out-of-plane actions.

Experimental tests on masonry have shown a dynamic enhancement of its strength properties when subjected to high strain rate loading [2-5]. As a result, a common approach to design dynamic loading is to conduct a linear static analysis of a particular masonry panel or structure and apply dynamic increase factors (DIFs) to the nominal strength of the masonry units and mortar. Such factors are derived from experimental tests [6] and are used to obtain an equivalent static representation of the dynamic structural response [7]. It is also possible to simplify the system into an equivalent single degree of freedom to derive panel endrotations and global displacements. The main drawback of these approaches is that local effects, such as behaviour after first crack, crack propagation, degradation and deformation of the masonry units and mortar, and brick-to-mortar interaction are not considered appropriately.

Other methods developed are non-linear finite element methods that aim to account for the local effects previously mentioned. There are three different approaches generally adopted in the multi degree of freedom domain: macro-modelling, which considers the masonry as two-dimensional elements assuming it is homogeneous, with a large number of assumptions that might not be realistic [8]; simplified micro-modelling or meso-modelling that discretises bricks as three-dimensional elements joined by a zero thickness mortar interface $[9,10]$; and detailed micro-modelling where both brick and mortar components are discretised [3,11]. Computational time plays an important role in the choice of approach taken. Nevertheless, this is becoming less of a challenge given the advances and access to powerful IT resources.

Several authors $[6,8,12,13]$ have identified the need for continuing development of these numerical modelling approaches to appropriately consider the variability present in masonry construction and its non-linear behaviour to give the most accurate predictions [3]. 


\section{BRICK-TO-MORTAR INTERFACE BEHAVIOUR}

\subsection{General overview}

In micro-modelling approaches, accuracy relies on understanding the behaviour of the brickto-mortar interface prior to, and after cracking, and being able to replicate it $[10,14,15]$. This interface presents a high level of variability due to the different compositions of the bricks and mortars used and its strength and behaviour is affected by the quality of the workmanship on site, water content of the masonry units and mortar, masonry units' shape and presence of voids as well as degradation due to weather conditions $[9,16]$.

In general, little attention has been given to the lack of perfect bonding between the mortar and brick, yet the quality of bonding is critical to the flexural performance of masonry when subjected to out-of-plane actions (static or dynamic). Sarhosis et al. [9] assessed low bond strength masonry walls with openings under vertical static actions and found that for this type of structure and loading conditions, the load at first cracking was mostly influenced by the joint tensile strength, whereas the ultimate loading was mostly influenced by the joint cohesion. However, in this study, the strength of the mortar was assumed using a deterministic approach.

Discussion exists on whether dynamic properties of bricks or mortar, or both, are to be tested or can be related to their static properties. Yan et al. [17] proposed an analytical expression for one-dimensional spalling of concrete and mortar, under dynamic loading, and discusses whether or not the dynamic strength of brittle materials can be regarded as an intrinsic material property. Burnett et al. [2] performed laboratory tests on masonry joints subjected to dynamic tensile loading and found a significant dynamic enhancement (DIF = 3.1 ) in the tensile strength at a strain rate of $1 \mathrm{~s}^{-1}$. Finite element modelling was used to prove this was due to the inherent partial variability of the brick-to-mortar bond strength and not a material characteristic. Chan and Bindiganavile [4] assessed the strain rate sensitivity of plain and fibre reinforced hydraulic lime mortar as opposed to conventional Portland cement mortar. The strain rates applied to the experimental tests varied from $10^{-6}$ to $1 \mathrm{~s}^{-1}$. It was found that apparent strength and stiffness under impact loading will experience an increase with strain rate and that the post peak flexural toughness factor decreased with strain rates, due to embrittlement of the fibres. Tensile strength is characterised by the modulus of rupture, which is higher in hydraulic lime mortars [4]. However, it was found in this study that fracture toughness in hydraulic mortars is more sensitive to strain rates than the modulus of rupture. DIFs for hydraulic lime mortars were found to be different to those for conventional mortar [4]. Pereira et al. [5] presents impact tests performed on clay brick samples with a drop weight impact machine with velocities ranging from 4 to $199 \mathrm{~s}^{-1}$ and derivation of DIFs.

\subsection{Failure criterion of brick-to-mortar interface}

In order to be able to model masonry behaviour at the global scale, it is important to understand how masonry behaves on the local scale. Establishing a failure criterion is an important aspect of the brick-to-mortar interface characterisation as failure tends to occur at the joint and not within the units themselves [12]. A good review on failure criterions is provided by Riddington and Ghazali [14]. One of the most widely adopted failure criterion for the brick-to-mortar interface is the Mohr-Coulomb criterion $[9,15,16,18]$. Physical tests have 
been performed and parameters for this failure criterion derived [16,18]. Wang et al. [15] presents a comparison where the interface is modelled using the Drucker-Prager and MohrCoulomb failure criteria, with the latter providing better results for load displacements and prediction of failure load at low levels of stress. Mohr-Coulomb failure criterion assumes a linear relationship between shear stress and normal stress at failure in a two-dimensional space. Drucker-Prager criterion is a three-dimensional generalisation of the Mohr-Coulomb failure criterion, assuming linear dependency between octahedral shear stress and octahedral normal stress at failure. Failure criterions can be governed by tensile and shear strength, or unit failure in tension and shear [11,19].

Triplet tests are used to characterise the shear strength of the brick-to-mortar interface [20], as opposed to couplet tests that are used to characterise the tensile strength at this interface. Triplet tests can be used for quasi-static and dynamic loading with different levels of precompression [14].

\section{UNCERTAINTY QUANTIFICATION}

Uncertainty propagation is used to account for the uncertainty present in any system. The uncertainties in masonry construction, as highlighted in Sections 1 and 3, are not generally accounted for in analysis and design, thus a deterministic approach is predominantly used. This paper focuses on the uncertainty propagation in the shear and tensile strength of the brick-to-mortar interface.

In order to perform uncertainty propagation, samples need to be generated to account for the lack of physical test data. There are various methods available to achieve this, however, Monte Carlo (MC) simulation has a consistent performance regardless of the dimension of the system and therefore is used in this study.

\section{METHODOLOGY}

A numerical model of a masonry triplet test has been developed to study the uncertainty in the brick-to-mortar interface and its effects on the strength of the interface under dynamic loads. The numerical model has been compiled in the same manner as that by Beattie [11] and validated against experimental data. The numerical model is coupled with an uncertainty propagation research-based software package to establish the effects of uncertainty at the brick-to-mortar interface on the failure load.

\subsection{Numerical modelling}

The numerical modelling was conducted using LS-DYNA [21], which is a multi-purpose non-linear finite element analysis software package. The numerical model consisted of a triplet test subjected to an impact load of 1,000 kN/s (Fig. 1a). A detailed micro-modelling approach is used, in which the brick, mortar and steel support plates are discretised by 1,000, 400 and 24 eight-noded fully integrated solid elements each (Fig. 1b). Input data were taken from Beattie [11], who conducted both triplet testing and finite element analysis. This input data were the result of an extensive iterative process to establish the dynamic properties for use in modelling. Brick and mortar materials are represented by a simple bilinear stress-strain material model whereas the steel plates are modelled with a simple linear elastic material model. The brick-to-mortar interface is modelled using a contact interface characterised by tensile and shear strength $\left(\sigma_{\mathrm{T}}, \tau\right)[21]$, whose failure criterion is defined in eqn. (1). The steel 


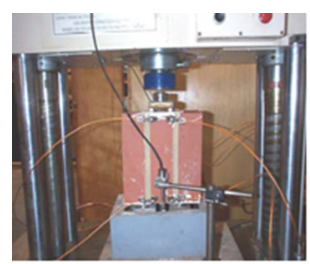

(a)
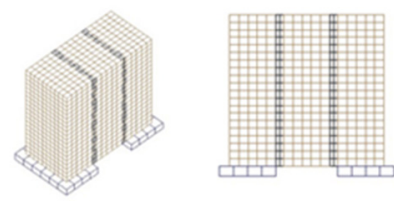

(b)

Figure 1: (a) Triplet test under dynamic loading [11]. (b) Triplet test model discretisation.

plates are vertically and horizontally restrained. The loading is applied uniformly to the top surface of the middle brick, increasing linearly with time for $0.035 \mathrm{~s}$ [11], to simulate a hammer dropping. Output plots were produced at $10^{-6} \mathrm{~s}$ intervals.

$$
\left(\frac{\sigma_{\mathrm{T}}}{\sigma_{\mathrm{T} \text { limit }}}\right)^{2}+\left(\frac{\tau}{\tau_{\text {limit }}}\right)^{2} \leq 1
$$

\subsection{Uncertainty propagation}

OpenCossan [22] was used to propagate uncertainty in the brick-to-mortar interface properties of the numerical model and to understand how much of an impact this has on the failure load at the interface. OpenCossan is a research-based software package used for uncertainty quantification. OpenCossan links to the numerical work conducted in LS-DYNA. One injector links the input keyword file of LS-DYNA with OpenCossan by means of a connector. The keyword file is manually modified to indicate the variables to which uncertainty will be propagated to, so these variables can also be identified in this injector. The variables are the shear and tensile strength of the contact interface. An extractor was defined, and link to the connector, to extract the contact forces at the interface from the output files. The work presented here involved sets of simulations using a high-performing cluster to reduce the computational time of the entire process. MC simulations were used, prescribing probability distributions to the brick-to-mortar interface random variables, i.e. tensile strength and shear strength. Each variable was assigned a normal distribution from which random values were sampled and obtained for each simulation and used as input for every finite element analysis. There were sets of 100 and 200 simulations performed, each simulation using a different combination of random variables. The whole framework, once set and with the variables defined, will run and perform every set of simulations automatically, with no need for human input during the process. Failure forces were stored and saved for every set of variable values used in each simulation.

\section{RESULTS}

\subsection{General overview}

The results of the analysis are presented in two sections. One regarding a single deterministic analysis performed in LS-DYNA of a masonry triplet test under impact loading and a second 
presenting the results from the uncertainty propagation at the brick-to-mortar interface using OpenCossan.

\subsection{Baseline model validation}

From the deterministic analysis the numerical failure load was found to be $25.90 \mathrm{kN}$ which is in reasonable agreement with the physical data obtained by Beattie [11].

The Von Mises principal stresses distribution is found to be as expected, symmetrical about the vertical axis (Fig. 2), and the reactions below the base plate added up to the total load applied. After load application, stresses propagated from the top surface of the middle brick through to the bottom. Two stress concentration areas are seen at the internal faces of the bricks where the bricks bare onto the steel plates. The stress at these points is higher than the stress at the top of the bricks, due to the three-brick sample trying to bend at the supports resulting in forces being distributed over a smaller surface area at these points. During the onset of $t=0.032239 \mathrm{~s}$, an out-of-balance stress distribution is observed (Fig. 3). This lack of symmetry just before failure can be observed in Fig. 4. Forces in the steel plates and contact interfaces increase linearly and in equal magnitude until the first brick-to-mortar interface fails, seen as a sudden drop in force at the base of one steel plate and brick-tomortar interface thus forcing the remaining steel plate and brick-to-mortar interface to carry

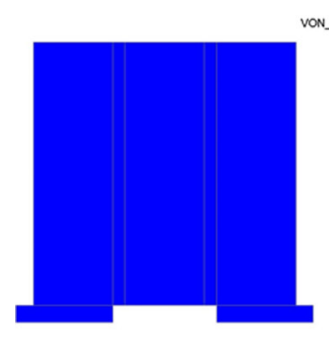

(a)

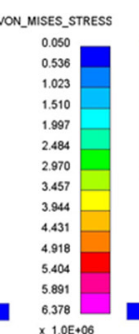

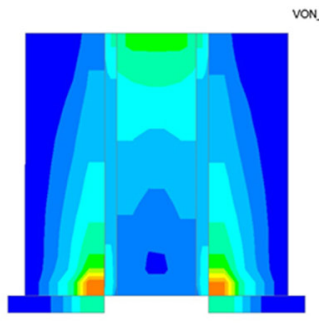

(b)

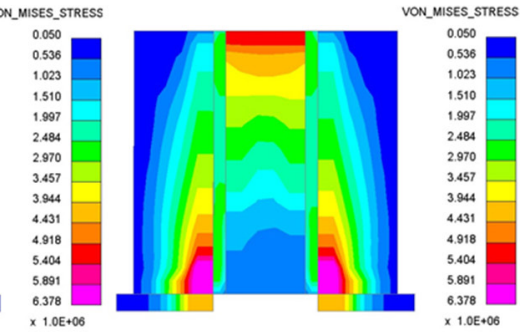

(c)

Figure 2: Von Mises stress (a) $t=0 \mathrm{~s}$, (b) $\mathrm{t}=0.016000 \mathrm{~s}$ and (c) $\mathrm{t}=0.030400 \mathrm{~s}$.

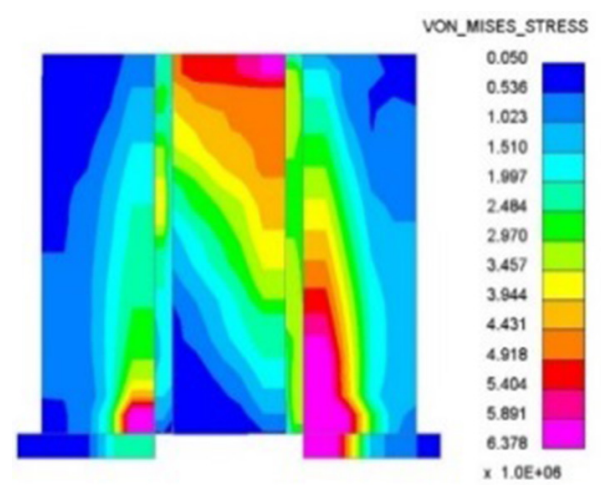

Figure 3: Von Mises stress $t=0.031900 \mathrm{~s}$. 


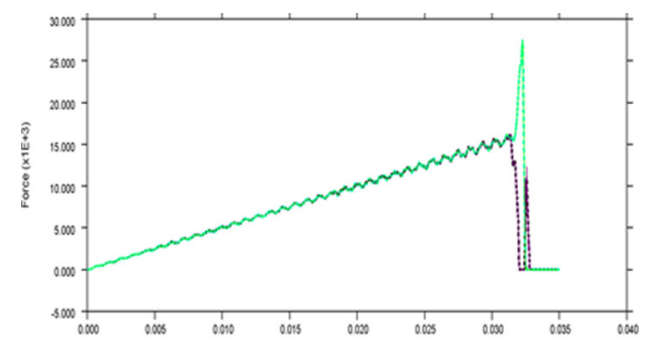

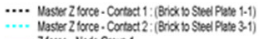
- 2 trace- Nose Grap 1

(a)

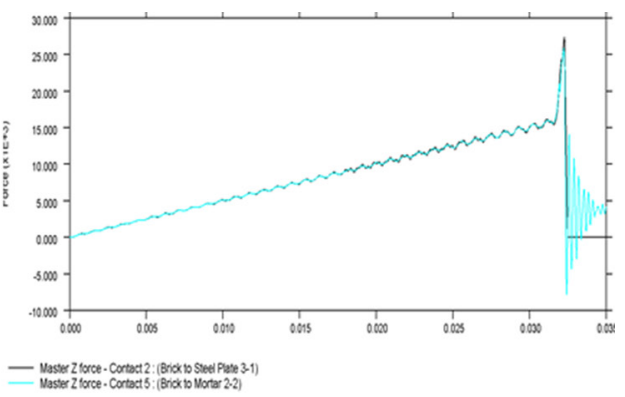

(b)

Figure 4: Force (N) vs time (s) of (a) nodal forces at the bottom of steel plate 1 (Node Group 1), bottom of steel plate 2 (Node Group 2), and contact forces at brick to steel plate interfaces. (b) Contact forces at brick to steel interface and brick to mortar failure interface.

the entire remaining load as shown by the spike in force, denoting when failure occurs. Output from both nodal forces at the bottom of steel plate and contact forces at the brick-tosteel plate interfaces are plotted in Fig. 4a, where it can be seen as they follow the same trend and are almost identical in value, as expected. Figure $4 \mathrm{~b}$ shows the agreement between the contact forces at the brick-to-mortar failure interface and its correspondent steel plate. This numerical model is therefore validated against both physical data and expected behaviour.

\subsection{Uncertainty quantification results}

Uncertainty was propagated in the brick-to-mortar interface. Normal distributions were assumed for a total of eight random variables; two at each of the four interfaces (Fig. 5). The mean for each distribution was taken as the deterministic value with $10 \%$ standard deviation. In total, four sets of simulations were carried out (sets 1-4) assuming uncorrelated and correlated variables and performing 100 and 200 simulations (Table 1). For the correlated sets, it was assumed that the shear and tensile strength at interface 1 had a strong correlation with the shear and tensile strength at interface 2 (Fig. 5) as most of the sources of uncertainty at both interfaces (e.g. composition of mortar, layering process and water content) would be the same. However, bonding conditions at either side of the mortar might not be the same. Hence, a correlation coefficient of 0.8 was taken. The same assumptions were adopted for interfaces 3 and 4 . The shear and tensile strength at interfaces $1 \& 2$ and $3 \& 4$ was assumed to have a correlation coefficient of 0.7 as the layering processes would be different between them. The tensile and shear strength remained as independent variables for all sets. Every set of simulations was treated independently.

The maximum interface force (failure load) was computed for each simulation and was used to plot the distribution of failure load for each set (Fig. 6). Maximum, minimum and mean failure load values were computed also. The failure load (F) was taken to be the load below which $5 \%$ of the samples fail and is presented in Table 2. For comparison, the load below which $95 \%$ of the samples fail was also calculated. 
Table 1: Simulation set properties.

\begin{tabular}{lcl}
\hline Set & No. of simulations & Correlation \\
\hline 1 & 100 & No \\
2 & 100 & Yes \\
3 & 200 & No \\
4 & 200 & Yes \\
\hline
\end{tabular}

Table 2: Uncertainty propagation output regarding failure load.

\begin{tabular}{lccccc}
\hline Set & $\begin{array}{c}\text { F for 5\% failing } \\
\text { samples }(\mathrm{kN})\end{array}$ & $\begin{array}{c}\text { F for 95\% failing } \\
\text { samples }(\mathrm{kN})\end{array}$ & $\begin{array}{c}\text { Mean F } \\
(\mathrm{kN})\end{array}$ & $\begin{array}{c}\text { Max F } \\
(\mathrm{kN})\end{array}$ & $\begin{array}{c}\text { Min F } \\
(\mathrm{kN})\end{array}$ \\
\hline 1 & 21.437 & 28.500 & 25.581 & 30.834 & 18.105 \\
2 & 18.149 & 29.349 & 25.462 & 29.984 & 17.869 \\
3 & 21.561 & 28.689 & 25.533 & 30.070 & 18.174 \\
4 & 18.312 & 29.642 & 25.653 & 31.167 & 17.954 \\
\hline
\end{tabular}

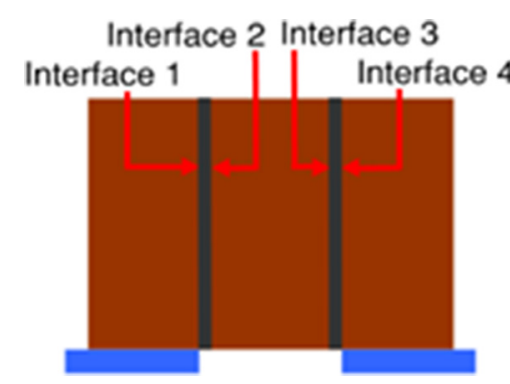

Figure 5: Triplet test interfaces.

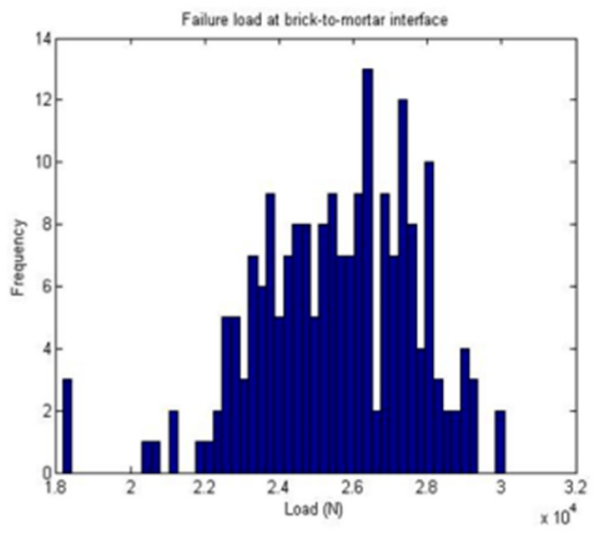

(a)

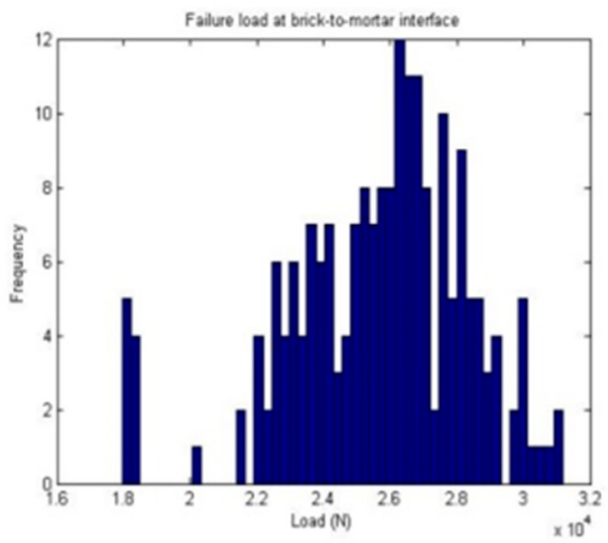

(b)

Figure 6: Failure load in Newtons for 200 simulations with (a) no correlation and (b) correlation between some variables. 
Table 3: Coefficients of correlation between variables and failure load.

\begin{tabular}{lrlr}
\hline Tensile strength interface 1 & 0.1171 & Shear strength interface 1 & 0.0725 \\
Tensile strength interface 2 & 0.0986 & Shear strength interface 2 & 0.1251 \\
Tensile strength interface 3 & -0.0248 & Shear strength interface 3 & 0.0061 \\
Tensile strength interface 4 & -0.0130 & Shear strength interface 4 & -0.1149 \\
\hline
\end{tabular}

\section{DISCUSSION}

From the uncertainty propagation results, mean values from all four sets (mean F, Table 2) differ by no more than $2 \%$ of the deterministic value obtained, as expected. However, if taken as a failure load (the value at which $95 \%$ of the samples survive) discrepancies are noticeable between both physical and the numerical data ( $\mathrm{F}$ for $5 \%$ failing samples, Table 2 ). In defining the criteria for failure load, the choice of the number of samples that should survive above this threshold load will have a great effect on the determination of such load. It can be seen in Fig. 6 that there is a gap in the frequency of occurrence in some of the values above the minimum, which explains the low failure loads, for $95 \%$ of samples surviving. However, the value obtained physically also presents uncertainty (e.g. due to measurement errors). In addition, some of the distribution parameters, such as standard deviation, and correlations between the variables have been assumed due to the scarce data; and other sources of uncertainty and variables have been kept constant.

It can be seen how accounting for uncertainty at the interface affects the load at which failure is reached. Correlation coefficients show that the relationship between each variable with the failure load presents hardly any linearity, as its absolute values are closer to 0 than to 1 (Table 3 ).

\section{CONCLUSION}

Numerical modelling using LS-DYNA to simulate masonry triplet tests under impact loading has been presented in this paper.

A working framework has been developed to link LS-DYNA and OpenCossan, to propagate uncertainty in the numerical modelling and perform a probabilistic analysis. It was found that uncertainty propagation in the tensile and shear strength of the brick-to-mortar interface, performed using MC simulations has an effect on the determination of the failure load at the interface. It also has an effect on the failure load and how it is defined in terms of load at which a maximum percentage of samples failing is achieved. The correlation between the random variables influences the final results also. It was found that the correlation between tensile strength and shear strength input and failure load output was not linear. Results obtained from a deterministic approach differ from those obtained from uncertainty propagation.

This feasibility study is part of a larger project that aims to fully characterise the response and resilience of masonry structures when subjected blast and seismic actions using a reliable probabilistic approach. Future work will involve the modelling of larger structures in a multi-scale manner, i.e. incorporating the smaller-scale characteristics into robust larger-scale models.

\section{ACKNOWLEDGEMENTS}

I would like to acknowledge the support provided by Dr Ryan Judge and Dr Greg Beattie and the technical support provided by Dr Matteo Broggi. The authors would like to acknowledge the gracious support of this work through the EPSRC and ESRC Centre for Doctoral 
Training on Quantification and Management of Risk \& Uncertainty in Complex Systems \& Environments.

\section{REFERENCES}

[1] Wang, J., Heath, A. \& Walker, P., Experimental investigation of brickwork behaviour under shear, compression and flexure. Construction and Building Materials, 48, pp. 448-456, 2013.

http://dx.doi.org/10.1016/j.conbuildmat.2013.07.025

[2] Burnett, S., Gilbert, M., Molyneaux, T., Tyas, A., Hobbs, B. \& Beattie, G., The response of masonry joints to dynamic tensile loading. Materials and Structures/Materiaux et Constructions, 40(5), pp. 517-527, 2007.

[3] Linse, T. \& Gebekken, N., Detailed micro-modelling of masonry under blast and earthquake loads. In Urban Habitat Constructions under Catastrophic Events, Naples, 2010.

[4] Chan, R. \& Bindiganavile, V., Strain rate sensitivity of plain and fibre reinforced hydraulic lime mortar. Department of Civil \& Environmental Engineering, MS thesis, University of Alberta, Canada, 2010.

[5] Pereira, J.M., Dias, A. \& Lourenco, P.B., Dynamic properties of clay brick at different strain rates. In 12th Canadian Masonry Symposium, Vancouver, British Columbia, Canada, 2013.

[6] Linse, T., Gebbeken, N., Araújo, T. \& Silva, R.M., Experimental investigations and validation of a new material model developed for masonry bricks. In 10th World Congress on Computational Mechanics, Sao Paulo, Brazil, 2012.

[7] Engineers, U.A.C.o., Structures to resist the effects of accidental explosions, Air force Engineer Support Agency: N.F.E.C, 1990.

[8] Wei, X. \& Hao, H., Numerical derivation of homogenized dynamic masonry material properties with strain rate effects. International Journal of Impact Engineering, 36(3), pp. 522-536, 2009.

http://dx.doi.org/10.1016/j.ijimpeng.2008.02.005

[9] Sarhosis, V., Garrity, S.W. \& Sheng, Y., Influence of brick-mortar interface on the mechanical behaviour of low bond strength masonry brickwork lintels. Engineering Structures, 88, pp. 1-11, 2015. http://dx.doi.org/10.1016/j.engstruct.2014.12.014

[10] Macorini, L. \& Izzuddin, B.A., A non-linear interface element for 3D mesoscale analysis of brick-masonry structures. International Journal for Numerical Methods in Engineering, 85(12), pp. 1584-1608, 2011.

http://dx.doi.org/10.1002/nme.3046

[11] Beattie, G., Joint fracture in reinforced and unreinforced masonry under quasi-static and dynamic loading, $\mathrm{PhD}$ thesis, Department of Civil Engineering, University of Liverpool, 2003.

[12] Rafsanjani, S.H., Lourenço, P.B. \& N. Peixinho, Dynamic interface model for masonry walls subjected to high strain rate out-of-plane loads. International Journal of Impact Engineering, 76, pp. 28-37, 2015.

http://dx.doi.org/10.1016/j.ijimpeng.2014.09.002

[13] Burnett, S., Gilbert, M., Molyneaux, T., Beattie, G. \& Hobbs, B., The performance of unreinforced masonry walls subjected to low-velocity impacts: Finite element analysis. International Journal of Impact Engineering, 34(8), pp. 1433-1450, 2007. http://dx.doi.org/10.1016/j.ijimpeng.2006.08.004 
[14] Riddington, J.R. \& Ghazali, M.Z., Hypothesis for shear failure in masonry joints. Proceedings - Institution of Civil Engineers. Part 2. Research and Theory, 89, pp. 89-102, 1990.

[15] Wang, J.Z., Heath, A. \& Walker, P., Numerical analysis of triplet shear test on brickwork masonry. In 2013 3rd International Conference on Civil Engineering and Building Materials, CEBM 2013, December 7, 2013-December 8, 2013. Hong Kong, China: Trans Tech Publications Ltd., 2014.

[16] Abdou, L., Saada, R.A., Meftah, F. \& Mebarki, A., Experimental investigations of the joint-mortar behaviour. Mechanics Research Communications, 33(3), pp. 370-384, 2006.

http://dx.doi.org/10.1016/j.mechrescom.2005.02.026

[17] Yan, C., Ou, Z.C., Duan, Z.P. \& Huang, F.L., An analytical approach to dynamic spalling of brittle materials. International Journal of Impact Engineering, 83, pp. 28-36, 2015. http://dx.doi.org/10.1016/j.ijimpeng.2015.04.001

[18] Rahman, A. \& Ueda, T., Experimental investigation and numerical modeling of peak shear stress of Brick Masonry mortar joint under compression. Journal of Materials in Civil Engineering, 26(9), 2014.

http://dx.doi.org/10.1061/(ASCE)MT.1943-5533.0000958

[19] Chisari, C., Macorini, L., Amadio, C. \& Izzuddin, B.A., An inverse analysis procedure for material parameter identification of mortar joints in unreinforced masonry. Computers \& Structures, 155, pp. 97-105, 2015. http://dx.doi.org/10.1016/j.compstruc.2015.02.008

[20] Ghazali, M.Z. \& Riddington, J.R., Simple test method for masonry shear strength. Proceedings of the Institution of Civil Engineers (London). Part 1 - Design \&amp; Construction, 85 pt 2, pp. 567-574, 1988.

[21] (LSTC), L.S.T.C., LS-DYNA Keyword User's Manual, 2007.

[22] CossanX. http://cossan.co.uk/software/open-cossan-engine.php 